\title{
Application of Quality Management Models Aiming Towards Innovation in Management at Vietnamese Universities
}

\author{
Nguyen Quang Giao, Huynh Ngoc Thanh \\ Center for Education Accreditation, The University of Danang, Danang City, Vietnam
}

\section{Email address:}

nqgiao@ac.udn.vn (N. Q. Giao), hnthanh@cea.udn.vn (H. N. Thanh)

\section{To cite this article:}

Nguyen Quang Giao, Huynh Ngoc Thanh. Application of Quality Management Models Aiming Towards Innovation in Management at Vietnamese Universities. Higher Education Research. Vol. 5, No. 2, 2020, pp. 52-59. doi: 10.11648/j.her.20200502.13

Received: March 26, 2020; Accepted: April 13, 2020; Published: April 30, 2020

\begin{abstract}
The quality management models are derived from the manufacturing sector and gradually applied to education in general and higher education in particular. There are many quality management models applied by universities around the world such as Organizational Elements Model, ISO 9000, EFQM, TQM, PDCA, etc. The application of quality management models in management has helped universities to ensure and improve the quality of training, meeting the needs of learners and employers. In fact, choosing and applying a quality management model of universities depends on the perception and level of quality management of that unit. In order to ensure and improve the training quality of the school as well as to meet the increasing requirements of society and learners about the quality of training, universities in Vietnam in the past 10 years have started applying quality management models in management. The application of quality management models in management with the basic functions of quality management clearly shows an interest in management innovation at the university. To face the challenges and opportunities of that process of international integration in education, each country needs to find out for itself the policies and strategies necessary for higher education to best carry out its mission in the production, dissemination and application of knowledge, meeting the country's socio-economic development needs. In this context, the quality assurance (QA) of higher education (HE) institutions in Vietnam is currently an urgent issue that is highly concerned by the Party, State and society. The current quality of education and training shows that the implementation of QA of many HE institutions in Vietnam is still not commensurate with the requirements for quality and effectiveness of education. It has not been accessible to the current standards. Even a few higher education institutions do not really appreciate the implementation of QA at their establishments. Therefore, the implementation of QA is an urgent requirement to comprehensively improve the quality of education - training, scientific research and community service, creating its own identity and improving competitiveness in a global context of education. The paper addresses the quality management models that are commonly applied in university management, while also addressing the basics for applying quality management models to drive management innovation at universities in Vietnam today.
\end{abstract}

Keywords: Quality Management, Quality Management Model, Higher Education, Training Quality, Vietnamese Universities

\section{Introduction}

The quality of education in general and the quality of higher education in particular are always the issues that receive the attention of the whole society. In the context of the current globalization, training quality of universities, in addition to meeting training objectives of the university, must also be directed to regional quality standards and world. Moreover, universities in Vietnam are now making efforts to internationalize their diplomas to create favorable conditions for students to find jobs as well as study at higher levels. In order to do that, one of the basic issues is that universities need to apply quality management models (standard management) in accordance with the conditions of schools in general and with Vietnamese higher education in particular. This is also a solution that contributes to renovating the management work 
in universities. Because quality management is a relatively new issue, it has only been mentioned in Vietnam in the past 10 years, so most universities are quite confused when choosing and applying quality management models and mostly subjective of each school. The application of the quality management model in accordance with the conditions and the quality management platform of the current universities are an important issue to ensure and improve the quality of training and at the same time contribute to the innovation of management work in the university.

Thus, these also show that the urgent need now requires education to develop, to innovate to be able to meet the goals of the country. Innovating education means appreciating and developing QA in higher education. Quality assurance is an important part in the overall teaching activities of all schools. Quality Assurance helps schools, teachers as well as the whole society be able to receive positive feedback in collecting information to capture the acquisition of learners' knowledge and skills, contributing to adjusting training activities of the school and teaching activity of the instructors. QA helps managers get the necessary information be able to devise appropriate policies to improve the quality of school training and encourage schools to have reasonable innovations.

\section{Quality Management and Quality Management Models in Education}

\subsection{Quality Management}

In education, people are increasingly focusing on the quality associated with the interests of learners and society. The universities without quality or with poor quality are synonymous with failure and waste in education. Quality is not naturally born; it is the result of a series of interrelated factors. Wanting to achieve the desired quality requires a proper management of these factors.

According to Feingenbaum A., quality management "is an effective unifying system of the various departments within an organization, responsible for implementing quality parameters, maintaining and improving it to ensure high production and consumption in the most economical way to satisfy the needs of consumers" and Kaoru Ishikawa defines "Quality management is the system of measures to facilitate the most economical production of products or services of quality that meet consumer requirements" [1].

Based on ISO 8042: 1994, Quality management is "all these operations management functions common to define policies, objectives and responsibilities and implement them by means such as planning for quality, inspection quality, quality assurance and quality improvement within the quality system" and ISO 9000: 2000 defines "Quality management includes coordinated activities to direct and control an organization in terms of quality" [2].

According to Waren Piper (1993), quality management requires a commitment to continuous improvement, including three activities [3]: Setting goals and standards; Assessing the situation with reference to the benchmark; Improving standard situation.

From the above definitions, it is possible to conceive:

1. Quality management is the term used to describe methods or procedures to check and evaluate whether the products meet the required quality parameters and purpose.

2. Quality management is standard management, keeping things in a stable and developing state, including three activities conducted simultaneously and continuously, including: setting goals and standards, assessing the situation with reference to the standards, and improving standard situation.

3. Quality management includes levels such as quality control, quality assurance and total quality management.

\subsection{Quality Management Models Applied in Education}

The quality management models are from the manufacturing sector. Facing the requirements of ensuring and improving the training quality of universities, quality management models have gradually been applied in university management. There are many quality management models applied by universities around the world in university management including four commonly used quality management models: Model of organizational elements, EFQM, ISO 9000, TQM.

\subsubsection{Model of Organizational Factors}

There are five factors to evaluate as follows [4]:

1. Input: Students, university staff, facilities, training programs, regulations, laws, finance, etc.

2. Training process: Methods and training process, training management, etc.

3. Training results: Degree of completion of the course, achieved competence and adaptability of students.

4. Output: Graduates, research results and other services to meet economic and social needs.

5. Effectiveness: The outcome of higher education and its impact on society.

\subsubsection{EFQM Model}

Commonly used in the quality management of European universities are nine criteria to evaluate the performance of the unit in all areas: Leadership, policies and strategies, human management, research scientific research, resources, process management, customer satisfaction, impact on society, performance of the unit. The EFQM 5-stage evaluation form for collecting and analyzing data on the school's quality of management based on the EFQM model to provide the School Board with the information needed to address, prevent and improve the management system. 


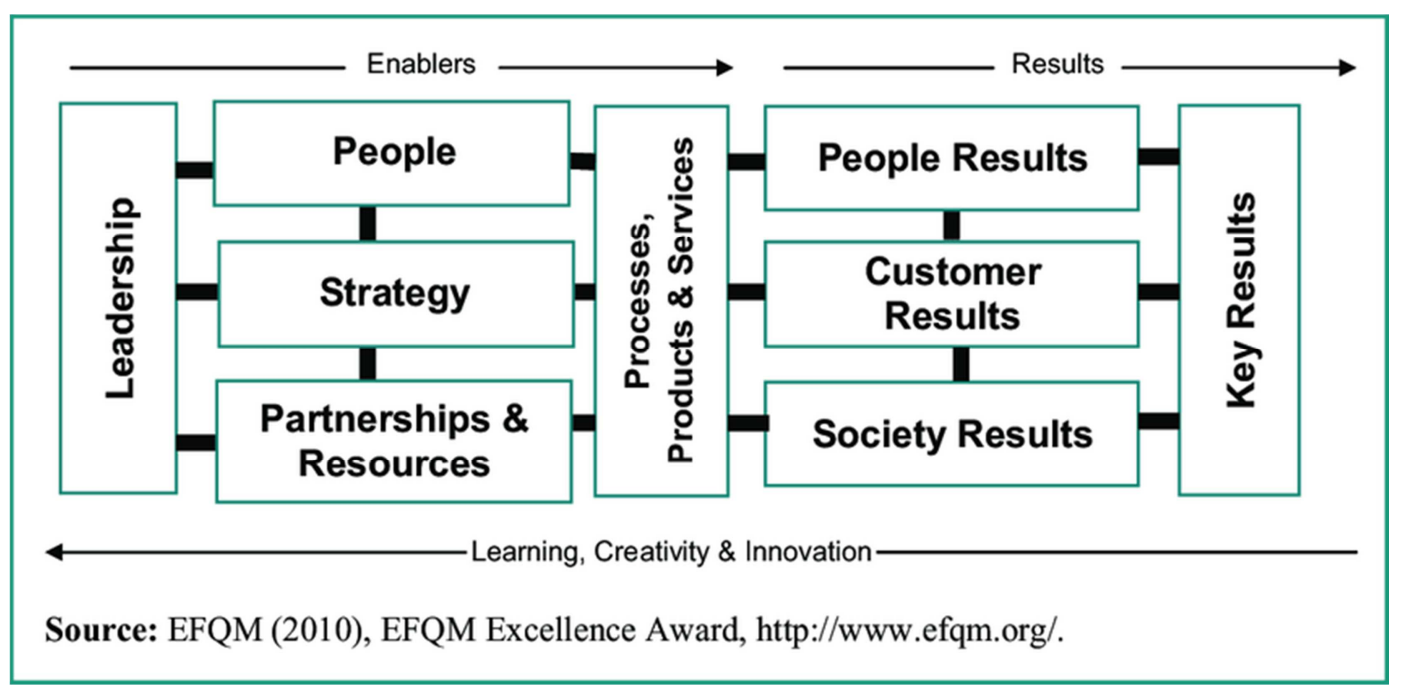

Figure 1. EFQM Quality Management Model.

\subsubsection{ISO $9000 \mathrm{Model}$}

The ISO 9000 series is a collection, summarization and standardization of orientation for achievements and experiences of QM of many countries, helping to manage businesses and public utility institutions more effectively. Therefore, ISO 9000 can be applied to all organizations, regardless of type such as enterprises, companies, public services, health, education, etc. The ultimate purpose of ISO 9000 is creating and ensuring quality products through the organization's management activities. ISO 9000 is an effective means of ensuring that key organizational processes are being managed in a consistent manner and in compliance with given standards. These standards are assessed and certified by an independent organization. The reevaluation and re-certification are carried out periodically. ISO9000 identifies four important elements of a quality system, including: Management Responsibility, Human Resources and Other Resources, Quality Systems, Interfaces with Clients.

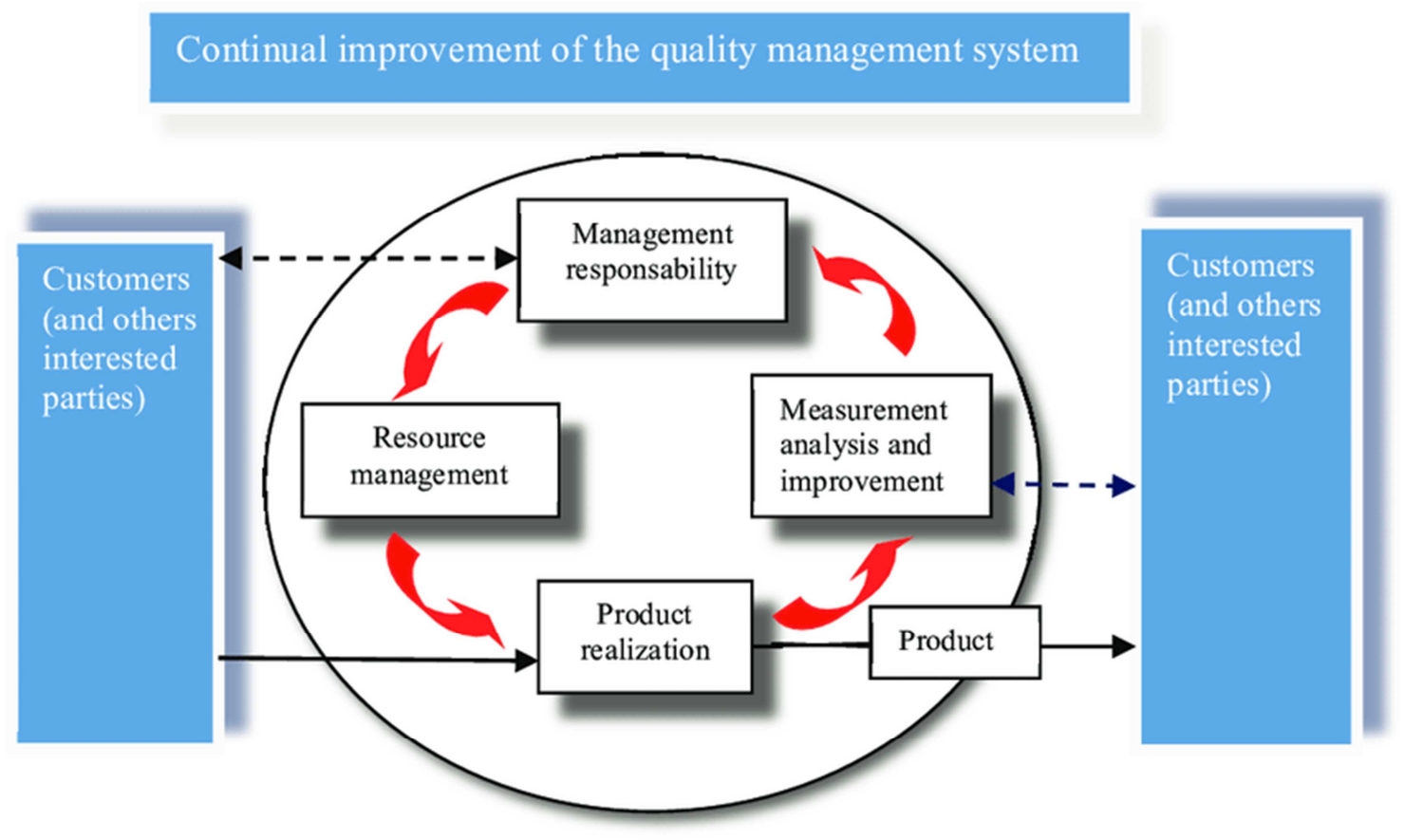

Figure 2. ISO 9000 Quality management model.

\subsubsection{Total Quality Management Model (TQM)}

The first step of establishing a comprehensive quality management system is from Total Quality Control - TQC (Total Quality Control) built by Mr. Armand V Feigenbaum from the 50s (XX century) when he was working at General Electric company as a leader of the company responsible for quality management and production management. From the $50 \mathrm{~s}$ and $60 \mathrm{~s}$ of the twentieth century, after Dr. Japan's visit to 
Japan of Dr. Deming and Dr. Juran, the company-wide quality control movement started and Mr. Ishikawa was a leader in that movement and he made an important contribution to the development of TQM. By the mid-1960s, the overall quality control activities began to spread in Japan - which is one of the prerequisites for the introduction of the TQM (Total Quality Management) model.

Like a QA system, TQM focuses on five areas: mission and customer focus; approach to systematic activities; the strong development of human resources; long-term thoughts; and utmost service (Sherr \& Lozier, 1991; Lewis \& Smith, 1994). According to Sherr and Lozier (1991), there are five main components that influence quality improvement in university: honesty, opinion sharing, patience, wholeheartedly working, and TQM theory [5]. In the five components above, only the last one can be taught and learned, as Figure 3 (ASQ, 2016):

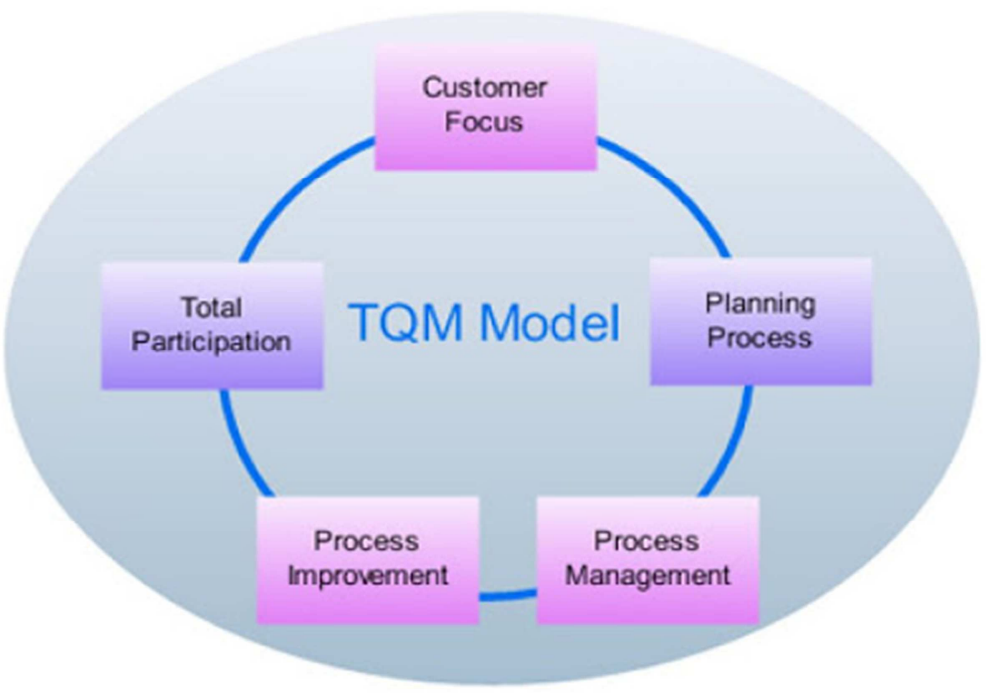

Figure 3. Total quality management model (TQM).

Total quality management (TQM) is the highest level of quality management, aiming to constantly improve the quality, every person in the organization, from leaders to employees is instilled with high quality culture. The basic characteristics of TQM emphasize that satisfying requirements and customer tastes are considered the top goals. TQM cares about the quality of the product and that quality must satisfy customers' needs; Building and developing a quality culture in the organization is a decisive factor for the goal of improving product quality; Commitments to publishing information publicly; Change quality culture through teamwork.

\subsubsection{PDCA Model of ISO 9001: 2015}

The layout model of ISO 9001: 2015 standard, while being faithful to the PDCA approach as in the previous version, has shown a number of significant changes in perspective and approach to the Quality Management System.

Firstly, the context of the organization with internal and external factors, needs and expectations of relevant interested parties was added as part of the "required input" for the Quality Management System in addition to the customer requirements. line. This demonstrates a consistent view of unifying the quality management system with the production and business processes of the organization, helping to ensure that the quality management system is consistent with and implementing internal and external environmental factors. business, strategic orientations and needs, expectations of relevant interested parties.
Secondly, the "expected output" of the Quality Management System according to ISO 9001: 2015, in addition to products and services along with customer satisfaction, includes the Quality Management System Results. This change reflects a more purposeful and resultoriented approach than the 2008 version and helps to ensure consistency in the risk management approach to transforming the "required inputs" on the strategic direction, needs and expectations of relevant interested parties.

Thirdly, in the model of the Quality Management System according to ISO 9001: 2015, the element of leadership is not in the steps of the PDCA cycle but in the center, there is an interactive relationship with the remaining groups of factors, including: Planning, Support and Operation, Performance Evaluation and Improvement. The central position demonstrates the meaning and influence of the "Leadership" element more naturally and clearly, and corresponds to the roles and responsibilities of leadership and management at all levels in the organization, in orienting, creating environment and promoting quality management system.

Fourthly, catching up with the breath of development in corporate governance, although still ensuring the auditable purpose, the layout and terminology used in the QMS model in the 2015 version have become self-sufficient and closer to reality of businesses. Compared to the "Leadership Responsibilities", "Resource Management", "Product Creation Process" and "Measurement, Analysis and Innovation", the names of "Planning", "Support and Operation" "Improving performance" and "Improving" are more closely linked to the 
organization's business management activities and the knowledge framework of other management areas. This can be a basis for believing that perceptions, beliefs and practices of the quality management system are tools and parts of the organization's overall management system that will be established and strengthened.

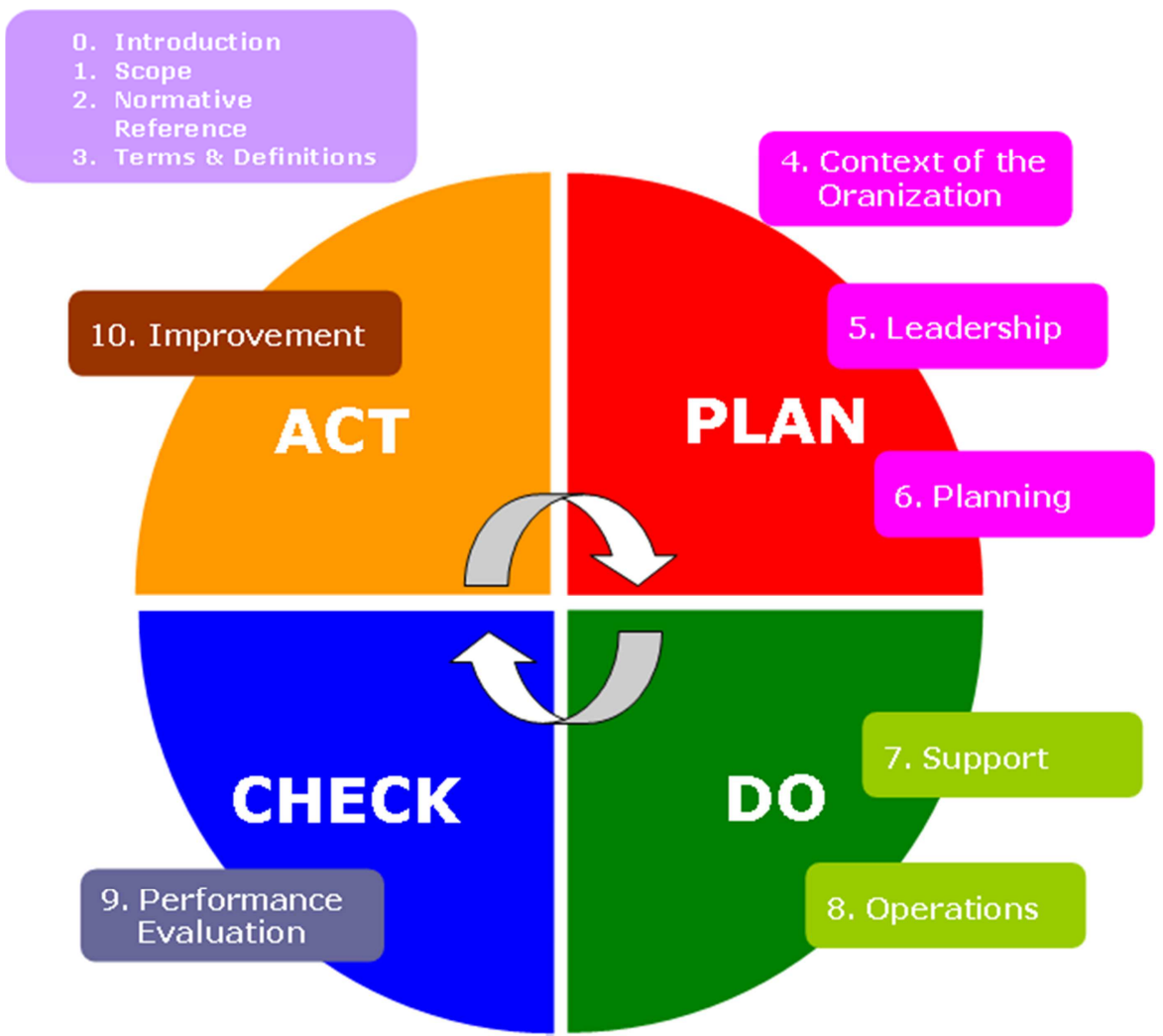

Figure 4. PDCA model of ISO 9001: 2015.

\section{The Need to Apply Quality Management Models in Higher Education in Vietnam}

In recent years, higher education in Vietnam has developed rapidly and strongly in the direction of integration with the general trend of the region and the world. The network of universities, types of training and training scale has also been rapidly increased to gradually meet the learning needs of the society. Universities and colleges are given more autonomy in enrollment, organizing training, evaluating and granting degrees, etc. However, more than ever, the quality of HE in Vietnam is the topic of social interest due to the fact that the quality of it is still limited and inadequate.

In fact, the activities of evaluation, QA and accreditation of HE in Vietnam have been focused on implementation, but not yet developed into a system and lack of uniformity. The Ministry of Education and Training's proposal to build and develop a system of education quality accreditation for higher education and secondary education period 2011 - 2020 states, "In fact, for nearly 30 years we have not really managed the quality of higher education because there are no output standards for universities and colleges (competency standards of graduates); the standards of many input factors have not yet been maintained (teachers, programs, curriculum, facilities); there are no specialized quality management agencies yet; there are no actual assessment and annual report on the quality of training of the university and the HE system" [6].

The management work at the university is still heavily administrative, hierarchical, not really promoting the autonomy, self-responsibility as well as creativity of the members in the school. Due to the lack of procedures, work instructions as well as criteria to assess the level of job completion accurately and explicitly, most of the members of the school do their jobs depending very much on the experience of themselves. This makes it difficult for individuals to perform work as well as managers. Although the inspection and evaluation at universities has been implemented, it has not been paid much attention; most of them have just stopped at the checking stage. The evaluation results have not been used for improvement activities to improve the quality of school management.

One of the causes leading to the situation mentioned above is due to the lack of accurate and appropriate evaluation criteria. This leads to the common situation in universities now that assessment and evaluation have not really become a motivation to attract members of the university to voluntarily and actively work. In addition, information on resources as well as school activities is not public to society. The feedback collection system has not been focused on or has not brought 
about real effectiveness in order to motivate the improvement of school management activities. Universities mainly focus on adjusting and correcting errors that appear in the process of managing and executing jobs; there is no mechanism or process to prevent errors in the process of management and implementation of schools. The quality of education is not really geared towards meeting social needs as well as employers. In addition, in the development of learning outcomes there are many cases that have not followed the scientific process, which is still subjective of each school. This has led many universities to adjust or lower their standards after a short time of application (popular with foreign language standards for graduates) [7, 8].

The above limitations are the expression of the functional management method being applied in management at universities in Vietnam today. Facing the increasing demands of society on the quality of education of universities, the innovation in management at universities in Vietnam is now very necessary and has an important significance, in which it is necessary to move gradually from functional management mode to the application of quality management models with many preeminent features.

\section{Difficulties in Applying Quality Management Models in Higher Education in Vietnam}

Quality management is derived from production and is applied to HE because the quality of HE needs to be managed. Although it is based on the general theory of QM, $\mathrm{QM}$ in higher education has certain characteristics. For higher education in Vietnam today when the new models of QM have been studied and applied in recent years, the application of the models of HE quality in Vietnam has its own difficulties and particularities.

Firstly, QM is standard management. This requires universities to publish the learning outcomes of training program of the school. In the current trend of integration and development, the curriculum standards of training programs are developed by universities based on the mission, goals of the school and the discipline, along with the needs of society in mind and progression to regional and world standards. Moreover, standard management will overcome the inherent limitations of the administrative management model under the command and subsidy regime.

For HE in Vietnam this is very important because many universities have not published the full learning outcomes of the majors or the standards have not met the basic indicators of the training program of the school. Therefore, most universities have a rather vague view of the quality of the school's training because the student's academic results are the basis for the schools to evaluate the quality of training products while the current assessment of students' study results and especially the level of the content of the test compared with the learning outcomes of the major/ subject is controversial. In addition, students do not have the basis for matching to their ability after completing the course/ subject. The Ministry of Education and Training has required universities to develop and publish learning outcomes for all majors and complete them before December 2010. However, in reality, there are still cases where the output standards of the university training majors of some universities have not been built in accordance with regulations. On the other hand, to manage the quality of HE in Vietnam, it is necessary to change the educational management method from the command and subsidy regime to apply the models of QM according to the quantified standards.

Secondly, it is necessary to clearly determine the level of QM appropriate to the national HE background. While all three levels of QM are aimed at ensuring that the products provided by HE institutions meet certain standards of quality, the choice and application of which level depends on the awareness and the background of QM of HE of the country.

With the awareness and quality foundation of $\mathrm{HE}$ in Vietnam, when QM issues are quite new and in reality in nearly 30 years we have not really managed the quality of $\mathrm{HE}$ as according to the Report of HE System Development, the solutions to ensure and improve the training quality that the MOET submitted to the National Assembly, QA is the most appropriate level of QM in accordance with the current conditions of HE in our country. On the basis of determining the appropriate QM level, QA will propose specific solutions to ensure and improve quality.

Thirdly, the QM of the university is to manage all fields and sub-fields to each specific job in order to ensure the quality from the specific job to the sub-field, the field that makes up the overall quality of the University. Quality is only created and maintained if and only if all members of the school voluntarily perform it, guarantee quality and complete the assigned work. To do so, universities need to raise awareness about quality culture within the university. In fact, the perception of the majority of university staff in Vietnam is that the quality of the school is the responsibility of the leading staff. This has led to the fact that the quality problem only stopped at the leadership level and encountered difficulties in implementing to the staff and teachers. Therefore, through meetings, seminars as well as administrative documents, universities need to disseminate and address the quality issues and quality related concepts to all officials and teachers from which they complete the assigned work actively and voluntarily and realize that the quality of the school is the responsibility of each officer and teacher.

Fourthly, it is suggested that universities should establish procedures and processes in management. Universities mostly manage schools as planned. This traditional management method is no longer really suitable with the current context when universities in the region and the world gradually come to recognize each other's qualifications/ training programs. To implement QM, universities necessarily build procedures and processes and implement management according to those procedures. On the basis of analyzing the quality management level in accordance with 
the current conditions of universities in Vietnam, universities need to establish procedures and processes for specific fields, sub-fields and jobs. Therefore, the quality of the school will be ensured when the procedures and processes are implemented by simple QA that QM is implemented through procedures and processes in all fields and sub-domains to each specific job of the school.

Fifthly, education is considered a special service so education also has customers. The problem of customer identification is an important issue in HE quality especially in the current competitive trend. In addition, it is necessary to evaluate training products through customer feedback as a basis for improving and implementing improvement procedures to ensure and enhance the training products of customers' school. In Vietnam, although there is still a lot of debate about the economic issue of education, in recent years $\mathrm{HE}$ is considered a special service. Therefore, customer identification is a practical task for universities to care about customer satisfaction. Universities need to periodically collect customer feedback on training products as a basis for improving the training quality of the school.

Sixthly, to promote QM activities, universities need to set up a specialized unit in charge of implementing HE quality assurance activities. In addition, schools need to pay attention to professional training for officials in QA work.

At the request of the MET, universities should establish quality assurance institutions for $\mathrm{HE}$, including centers or specialized departments; qualified staff to carry out assessment activities to maintain and improve the quality of school activities Schools need to send officials to participate in regular training courses or domestic and foreign training courses on QAS. In addition, the school needs to create favorable conditions and incentives (reducing teaching hours, reasonable rewards...) in order to encourage staff to do QA work.

\section{Some Basic Solutions to Apply Quality Management Models in University Management in Vietnam}

Choosing a quality management model suitable to the practical conditions of the school. QM and QM models are relatively new concepts to universities in Vietnam today. Therefore, based on the quality and realistic conditions of the university, universities need to choose a QM model in accordance with their conditions. In fact, most universities in Vietnam choose ISO 9000 model to apply in school management. However, the problem is that schools need to analyze the realistic conditions of their school to choose the appropriate quality management model to apply to ensure and improve the quality of training products and contribute to the innovation school management.

Developing a plan to apply an appropriate and feasible quality management model. Based on the selected QM model, universities develop plans to apply appropriate and feasible quality management models with realistic conditions, in which tasks to be implemented should be clearly stated with specific timelines and results to be achieved, for example compiling manuals; training for managers, lecturers and students; implementing application of QM model; inspecting and evaluating the application of quality management model;

Ensuring the necessary conditions to apply the quality management model. The application of the quality management model in university management requires the university to ensure the necessary conditions of human resources, funding, facilities and equipment. In order to apply the successful quality management model, universities need to invest in a team of knowledgeable personnel in the quality management of higher education in general and quality management models in particular by sending officials to participate in regular training courses or domestic and foreign training courses on quality management. In addition, the school needs to invest in facilities and necessary equipment such as computers, photocopiers and computer software. In addition, prepare the budget for inviting external consulting department to evaluate the process of applying the quality management model in school management.

Fulfilling the leaders' commitment to applying the quality management model in school management. This is an important issue because the application of the quality management model is only effective with the commitment of the school leaders. Leaders must believe in the results achieved when applying a quality management model and be committed to applying a quality management model. This commitment will create a close relationship between the school's mission, goals and quality policies and goals. The quality management model will not be effective, or even it is not applied without the leaders' thorough commitment. Therefore, in the process of applying the quality management model, there must be a written commitment of school leaders to the school's quality policy as well as compliance with the implementation of the contents of the management model quality of school leaders.

Establishing the quality management department of the school. Universities need to set up a unit (Department, Team) to perform quality management tasks with a staff of 4-5 people, of which at least 2 full-time officials are needed to help the school's leaders monitor and examine the process of applying the QM model in management. Currently, because the QM documents in general and the QM model in particular are mostly written in English, schools should pay attention to their foreign language skills when selecting and arranging staff to perform QM work of the unit.

Organizing training on the contents of the quality management model. The QM model can only be applied and effectively applied when and only if the members of the school voluntarily take responsibility for seriously implementing the contents of the quality management model. Therefore, the school needs to organize training so that the management staff, lecturers and students understand the contents of the QM model the school chooses to apply. From there, they voluntarily and fully implemented the contents of the QM model in order to contribute to the successful 
application of the school's QM model. In addition, the school needs to develop a quality manual for the contents of the QM model in order to create favorable conditions for application.

Applying the contents of the quality management model. The school should hold a ceremony to announce the application of a QM model to mark the start of the implementation of the school's QM model. This is also a public form of notice of the school about the application of QM model to "customers" and all officials, lecturers and students. The school needs to implement fully and synchronously the contents of the QM model in all fields managed by the school to ensure and improve the quality of the school.

Examining and evaluating the application of the quality management model. When the contents of the QM model are implemented, the school should organize the monitoring, inspection and evaluation of the performance of the contents as a basis for adjustment if any errors appear during the process of application as well as improvement and completion of the contents of the QM model with the motto directed to satisfy learners' needs.

\section{Conclusion}

In the context of strong globalization today, the quality of education of Vietnamese universities is not merely meeting national standards but also aiming to meet regional and international standards. To do so, universities must take strong innovative steps in school management towards standardization. In particular, the selection of QM models that are suitable to the practical conditions and quality management platform of the university is considered as one of the important solutions to ensure and improve the quality. The quality of the school also contributes to the renovation of HE management in Vietnam today.

In the process of approaching many quality assurance and testing models in the world as well as in the region, the model to ensure the quality of education in Vietnam is gradually being stabilized, consistent with the QA models of many other countries, especially the models of Europe, Asia Pacific, AUN - those models are continuously developed on the common model of Europe and America. However, in order to ensure Vietnam's education quality model to be developed in a sustainable manner, it is necessary to:

1. Make efforts to build the QA system within the educational institutions to gradually establish a quality culture within those educational institutions with the aim of making all members of the school understand, care and desire to improve the quality improvement.

2. Strengthening teaching quality assessment, program evaluation, internal audit and increasingly expanding the scope of application. Self-assessment should be focused as a tool to improve education quality.

3. Enhancing the autonomy of the Center for Quality Assurance in order to ensure the objectivity in the evaluation, thereby, the quality of education of $\mathrm{HE}$ institutions can meet the international and regional standards. At the same time, the capacity of local experts should be enhanced because external assessment is an objective way of reflecting the status of HE institutions from an external perspective.

\section{References}

[1] Ta Thi Kieu An, Ngo Thi Anh, Nguyen Van Hoa, Nguyen Hoang Kiet, Đinh Phưong Vuong (2004). Quality management in organizations. Statistical Publishing House, Hanoi.

[2] Le Anh Tuan, Minh Duc (2006). ISO 9000 Implementation guidance document. Youth Publishing House, Ho Chi Minh city.

[3] Warren Piper D. (1993). Quality Management in Universities. AGPS, Canberra.

[4] Nguyen Duc Chinh (2002). Quality accreditation in higher education. Hanoi National University Publishing House, Hanoi.

[5] Sherr, Lawrence A., Lozier, G. Gredgory (1991). New directions for institutional research: Total quality management in higher education. A Wiley Company, USA.

[6] The Ministry of Education and Training (2010). Project on building and developing the education quality accreditation system for higher and secondary education in the 2011-2020 period. Hanoi.

[7] Nguyen Quang Giao (2012). Applying quality management on management of universities in Vietnam. The International Journal of Educational Administration and Development, 3 (2), pp. 1-14.

[8] Nguyen Quang Giao (2015). Quality management in higher education. Hanoi National University Publishing House.

[9] Nguyen Duc Chinh (2008). Assessing the quality in education. Department of Education, Hanoi National University.

[10] Harvey L., Green D. (1993). Defining quality. Assessment and Evaluation in Higher Education 18 (1).

[11] Russo C. (1995). ISO 9000 and Malcolm Baldrige in Training and Education: A Practical Application Guide. Charro, Kansas City.

[12] Sallis E. (1993). Total Quality Management in Education. Kogan Page, London.

[13] Vietnamese Government (2007), Decision approving the master plan for the network of universities and colleges in the 2006-2020 period, Hanoi.

[14] Anastasia Papanthymou \& Maria Darra (2017). Quality Management in Higher Education: Review and Perspectives. Higher Education Studies; Vol. 7, No. 3. DOI: 10.5539/hes.v7n3p132.

[15] James Williams (2020), Quality in Higher Education, Volume 26, Number 1. DOI: 10.1080/13538322.2020.1743501.

[16] Lewis, R. G., Smith, D. H. (1994). Total quality in higher education. Delray Beach, FL: St. Lucia Press.

[17] Theodor Leiber (2019). Impact Evaluation of Quality Management in Higher Education. Routledge. 